\title{
POLÍTICAS PÚBLICAS PARA A QUALIDADE DA EDUCAÇÃO BRASILEIRA: ENTRE O UTILITARISMO ECONÔMICO E A RESPONSABILIDADE SOCIAL
}

\author{
Marília FonseCA*
}

\begin{abstract}
RESUMO: O objetivo do presente texto é compreender como o conceito de qualidade se configurou nos planos brasileiros de educação. Parte do pressuposto de que a política educacional, nas quatro últimas décadas, oscilou no confronto entre as propostas oriundas dos movimentos sociais e as políticas públicas fixadas pelos sucessivos governos. Em meio a essas demandas, foram produzidos diferentes significados para a qualidade da ação educativa, quer expressem os princípios humanistas, privilegiando a cidadania e a emancipação dos sujeitos, quer se voltem para a preparação dos indivíduos como meros produtores e consumidores no mercado.
\end{abstract}

Palavras-chave: Qualidade educacional. Educação básica. Políticas educacionais.

Public POlicies For THE QUaLITY of BRAZILIAN EDUCATION: BETWEEN ECONOMIC PRAGMATISM AND SOCIAL RESPONSIBILITY

ABSTRACT: This text strives to understand the concept of quality that underpins the plans for Brazilian education. It assumes that, over the last four decades, educational policies have oscillated according to the confrontation between social movements and educational projects determined by the successive Brazilians governments. Either expressed in terms of humanitarian principles stressing citizenship and individual emancipation or of preparation of subjects as producers and consumers in the market dynamic, such demands have produced different meanings for the quality of education.

Key words: Educational quality. Basic education. Educational policies.

Doutora em Ciências da Educação e pesquisadora associada da Faculdade de Educação da Universidade de Brasília (UnB).E-mail: fmarilia@unb.br 


\section{Introdução}

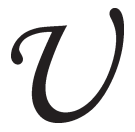

ma reflexão acurada com respeito à qualidade da educação supóe apreendê-la no âmago da dinâmica socioeconômica e cultural de um país. Implica perceber como a política educacional interage com os projetos nacionais de desenvolvimento, os quais, por sua vez, articulam-se, de forma mais ou menos autonômica, com as sucessivas mutações da economia mundial; supóe perceber a sua interlocução com os movimentos pedagógicos e metodológicos e, ain$\mathrm{da}$, com as demandas da sociedade organizada, mais especificamente, aquelas que partem dos educadores, muitas vezes sustentando posições contrárias à política oficial. No seio dessa dinâmica, são produzidos valores que se traduzem em diferentes sentidos para a qualidade. Observada pela função social, a educação de qualidade se realiza na medida em que logre preparar o indivíduo para o exercício da ética profissional e da cidadania. Supõe, ainda, educá-lo para compreender e ter acesso a todas as manifestações da cultura humana; do ângulo puramente pragmático, a educação de qualidade se resume ao provimento de padróes aceitáveis de aprendizagem para inserir o indivíduo - como produtor-consumidor - na dinâmica do mercado.

Alguns autores tomam como referência a função equalizadora da educação, que exige a responsabilidade do Estado em garantir a oferta, o acesso e a permanência de todos no sistema de ensino. Neste caso, a qualidade se articula à noção do direito individual. Oliveira (2007) considera que a ampliação do acesso à escola fundamental que se deu nas últimas décadas constitui per se um indicador de que a qualidade educacional está melhorando, pelo fato de que beneficia a população historicamente excluída. A ampliação da escola fundamental, por outro lado, estimula a procura por níveis subsequentes de ensino e produz novos desafios para o sistema, entre eles, a superação do aprendizado insuficiente e dos altos índices de reprovação e de abandono escolar. Além disso, a expansão de vagas, segundo Cunha (2007), atrai para a escola diferentes usuários e, por conseguinte, surgem novas exigências para a qualidade.

Outros estudos examinam a qualidade do ponto de vista das políticas governamentais dirigidas para o sistema, como avaliação externa, o financiamento público, a inovação tecnológica, a formação de 
quadros administrativos e docentes. Ou, ainda, a examinam a partir da dinâmica interna das instituições escolares e universitárias, enfocando a gestão institucional, a autoavaliação, o currículo. Estes enfoques não são excludentes; antes, evidenciam os diferentes aspectos pelos quais a qualidade pode ser apreendida.

O presente texto busca analisar a qualidade, conforme esta se expressa nos planos nacionais de educação produzidos e implementados no Brasil a partir da década de 1960 . Leva-se em conta que a ação educativa não é mero reflexo dos planos oficiais. Primeiro, porque a política educacional é condicionada por fatores externos ao governo central de um país, entre eles, a autodeterminação dos entes federados (estados e municípios); as demandas forjadas no campo da economia e do mercado de trabalho e as que provêm da mobilização de setores reivindicativos da sociedade. Leva-se, ainda, em conta que as metas fixadas em planos de longo prazo nem sempre se sustentam no decorrer do tempo, o que demanda modificações e adaptações. Não obstante essas ressalvas, a decisão de centrar a presente análise nos planos justifica-se pelo fato de que estes expressam os marcos ideológicos que orientam a política educacional de cada governo. Estes determinam as prioridades do financiamento governamental, as quais, por sua vez, podem influenciar as decisões em diferentes esferas administrativas do sistema. Os planos, portanto, fixam valores e diretrizes que devem ser conhecidos e debatidos em todas as instâncias responsáveis pela ação educativa e, obrigatoriamente, com a participação direta dos profissionais da escola.

Para resguardar a fidedignidade dos fatos históricos, recorri a alguns autores cujas obras são indispensáveis para a análise do tema aqui tratado, entre eles, Baia Horta (1982), Schwartzman et al. (1984), Saviani (2007) e Vieira (2007).

Como a qualidade se configurou nos primeiros planos educacionais brasileiros

A década de 1960 representou um marco na educação brasileira, particularmente pela promulgação da primeira Lei de Diretrizes e Bases da Educação (1961) e também pela implementação dos primeiros planos educacionais. É preciso levar em conta que a ideia 
Políticas públicas para a qualidade da educação brasileira...

de planejar a educação já vinha amadurecendo, desde o início da década de 1930, pela atuação dos educadores conhecidos como pioneiros ou renovadores.

Como nos mostra o estudo de Baia Horta (1982), os pioneiros, reunidos na Associação Brasileira de Educação ( $\mathrm{ABE}$ ) orientavam-se por valores democráticos de universalização do acesso à escola e de igualdade de ensino para todos. Incentivavam a qualidade metodológica da educação básica, pela adoção de uma pedagogia que facilitasse a individualização do educando pela atividade livre e espontânea; que se pautasse por um método ativo, estimulando a atividade criadora da criança por meio do exercício prático. A intenção era substituir o conceito estático por um conceito dinâmico de ensino. A IV Conferência Nacional de Educação, promovida pela ABE em 1931, resultou numa proposta conhecida como Manifesto dos Pioneiros, cujo objetivo era fundamentar um futuro plano nacional de educação. A Constituição de 1934 incorporou o sentido democrático do Manifesto, estabelecendo o ensino primário integral, gratuito, de frequência obrigatória e extensivo aos adultos. Para garantir a qualidade para a oferta ampliada de ensino, estabeleceu a vinculação de recursos e a destinação de fundos especiais para a educação, na esfera da União e dos estados, além do estabelecimento de concurso público para o preenchimento dos cargos do magistério. Além disso, a Constituição assegurou ao recém-criado Conselho Nacional de Educação a competência para elaborar um futuro plano nacional de educação e também participar da distribuição dos fundos especiais.

Com a instauração do Estado Novo, a proposta dos educadores, assim como a própria Constituição de 1934 tiveram vida breve. O processo de elaboração do plano educacional arrastou-se até 1937, quando foi apresentado à presidência da República como projeto de lei. Tampouco foi aprovado, em virtude do fechamento do Congresso. Durante esse período, a influência dos pioneiros foi arrefecida em virtude do estilo centralizador do governo e do fortalecimento de outras demandas sociais que conflitavam com a orientação dos educadores da ABE. Prevaleceu a diretriz imposta pelo Estado Novo, apoiado por setores sociais que a ele se uniam ideologicamente. Os militares e os católicos (estes últimos agremiados na Confederação Católica Brasileira de Educação) apoiavam o governo e lograram agregar suas propostas no novo plano de educação que seria apresentado ao Congresso em 1937. 
Inseriu-se o ensino religioso e a moral e cívica no nível básico de ensino, como espaço para a aprendizagem de valores como hierarquia e disciplinamento dos homens e da sociedade. Tais valores, que serviam ao pragmatismo do projeto governamental, passaram a constituir referência para a qualidade do ensino público: a formação de um homem útil e disciplinado para um Estado que se queria moderno, industrial e nacionalista (Brasil/Câmara Legislativa, 1937).

Segundo Schwartzman et al. (1984), a política educacional do Estado Novo privilegiou a formação para o trabalho, mediante a organização do ensino básico por ramos profissionais que correspondiam à divisão econômico-social do trabalho e das classes sociais. Propunhase, assim, uma educação diferenciada para a elite, para a mulher e para aqueles que comporiam o grande exército de trabalhadores para dar suporte ao projeto industrial do governo. Para estes últimos, a educação inicial deveria ocorrer fora do sistema regular e com a simplificação dos conteúdos, de acordo com as ramificaçôes do ensino.

Ainda que o plano de 1937 não tenha sido aprovado pelo Congresso, devido à resistência de segmentos da sociedade, especialmente os educadores, sua orientação doutrinária deu o tom da qualidade da educação brasileira nos anos que se seguiram. A análise histórica de Vieira (2007) mostra que a queda do Estado Novo (com a eleição de Eurico Gaspar Dutra, em 1945) não implicou mudanças significativas na linha do governo, embora, no início, tenha restabelecido o estado de direito e a autonomia federativa. Dutra imprime, no período seguinte, um veio intervencionista que durou até a volta de Getúlio Vargas, eleito para o período 1950-1954.

O governo democrático de Kubitschek, eleito para o período 1956-1961, deflagrou uma política de desenvolvimento sistematizada no chamado programa de metas. A educação foi incorporada ao programa com o propósito de preparar pessoal técnico para a implantação das indústrias de base. Nesse período, a vinculação entre educação e economia ganhou destaque internacional pela emergência da teoria do capital humano e do enfoque de mão-de-obra (man-power approach). Tal enfoque é um método de planejamento que consiste em determinar as metas de um plano de educação, com base na demanda do mercado de trabalho, especialmente quanto ao perfil e ao quantitativo de trabalhadores. Articula-se com a teoria do capital humano, segundo a qual o desenvolvimento dos recursos humanos pelo 
Políticas públicas para a qualidade da educação brasileira...

sistema educacional é um requisito essencial para o crescimento econômico dos países. A educação deveria, portanto, produzir competências técnicas para o emprego, de forma a agregar valor aos recursos humanos no mercado.

Devido ao destaque internacional, a vinculação educação-economia constituiu tema central das reunióes interamericanas de ministros da educação, convocadas pela OEA no final da década de 1950 . Desses fóruns originou-se a recomendação para que os países incorporassem a educação aos seus planos econômicos. No Brasil, a educação foi integrada ao programa de desenvolvimento do governo de Kubitschek, como uma das metas de sustentação do setor das indústrias de base.

O período de 1956 a 1963, que abarcou os governos democráticos de Kubitschek a Goulart, foi profícuo para a mobilização dos educadores, que voltaram a debater as suas ideias em fóruns nacionais. Os debates concentravam-se nos compromissos assumidos nas conferências internacionais, notadamente as que foram realizadas em Punta del Leste e Santiago do Chile, em 1961 e 1962. Estas últimas contaram com o patrocínio da OEA e de um programa de cooperação técnica e econômica do governo norte-americano: "Aliança para o progresso". Além do aspecto doutrinário que recomendava a integração da educação ao desenvolvimento econômico e social, as conferências estabeleceram metas decenais para a educação na América Latina.

Os intelectuais reunidos no Instituto Superior de Estudos Brasileiros (ISEB), dedicado ao estudo das ciências sociais, contrapunham uma alternativa social ao enfoque econômico defendido nos fóruns internacionais. Para eles, a educação não deveria reduzir o saber exclusivamente a assuntos de natureza técnica e a serviço de um projeto de desenvolvimento. Deveria abrir a percepção do educando para compreender as condiçôes políticas e ideológicas com que se defronta e prepará-lo para o empenho coletivo de superação do estado de atraso do país (Baia Horta, 1982).

Os educadores, entre eles Anísio Teixeira e outros membros do então Conselho Federal de Educação, criticavam a inadequação das metas internacionais às condiçôes socioeconômicas de cada país. Contrariando o enfoque economicista das conferências internacionais, Anísio Teixeira imprimiu um sentido filosófico-humanista ao plano de 1962: 
“A educação não é um bem acessório, mas uma condição sine qua non para que o brasileiro se torne um cidadão, possa exercer seus direitos políticos, seu poder econômico e viver decente e dignamente" (Brasil/ MEC, 1962, p. 60). Além disso, os educadores buscaram resguardar o enfoque cultural herdado dos pioneiros: a oferta educacional seria balizada pela demanda social coletiva, constituída pela soma de todas as demandas individuais, e que levasse em conta as condições econômicas, políticas e culturais do país ${ }^{1}$ (Brasil/MEC, 1963).

Pela intervenção desses educadores, as metas quantitativas dos primeiros planos de educação foram adaptadas à realidade brasileira. ${ }^{2}$ Do lado doutrinário, as propostas do capital humano e do enfoque de mão-de-obra foram mencionadas como meio de lograr a integração entre educação e desenvolvimento econômico.

\section{Articulação entre os planos educacionais e os programas estratégicos para o desenvolvimento}

Com a instauração do governo militar, o Plano 1963-1965 foi revisto, com o objetivo de adequá-lo à realidade brasileira, tal como a compreendia o novo governo. As metas seriam fixadas, rigorosamente, pelo "estabelecimento de ações e de recursos financeiros para vencer os deficits de educação plenamente justificáveis” (Brasil/MEC, 1965, p. 21). A gestão educacional passou a ser orientada pelo Decreto governamental n. 200, de 1967, que deflagrou uma reforma administrativa em todo o serviço público brasileiro. No Ministério da Educação, o processo foi iniciado pela Reforma n. 666.296/70, desdobrada em uma série de outras ações ao longo das décadas de 1970 e 1980. De forma esquemática, as principais características são: ênfase aos aspectos organizacionais (meios) e não a aspectos substantivos ou finalísticos da educação; organização das ações por projetos prioritários e campanhas de caráter transitório; criação de grupos-tarefa para gerir as ações transitórias e descentralizadas; participação das empresas privadas e governamentais de consultoria (nacionais e estrangeiras), no processo de modernização administrativa, entre elas a Agência Norte-Americana para o Desenvolvimento Internacional (USAID), que já cooperava com o Ministério desde a década de 1960. Posteriormente, fizeram-se presentes outras agências de cooperação técnica e financiamento - o Banco 
Políticas públicas para a qualidade da educação brasileira...

Interamericano de Desenvolvimento (BID) e o Banco Mundial (BIRD). A partir dos anos de 1980, este último desempenhou um papel decisivo na agenda educacional brasileira.

No início da década de 1970, o sistema educacional ajustou-se à estrutura da reforma administrativa e ao modelo de crescimento implementado no país. Os planos educacionais foram incorporados aos programas estratégicos dos governos militares, sendo elaborados segundo o enfoque da Administração por Objetivos (APO). ${ }^{3}$ Concebida por Peter Drucker para o campo empresarial, a APO fundamentou a reforma administrativa que reestruturou o serviço público brasileiro (Decreto-Lei n. 200/67). O Ministério da Educação incorporou os preceitos da APO, entre eles a prioridade para o desenvolvimento de recursos físicos, materiais e humanos, os últimos devendo constituir um todo homogêneo do sistema. Este preceito servia aos objetivos da doutrina de segurança nacional: ao mesmo tempo descentralizada e controladora, privilegiava a organização formal e recusava o conflito ideológico e a intervenção de grupos informais nas instituições educativas. Ao afirmar a padronização como princípio, a educação distanciou-se ainda mais da pedagogia social dos pioneiros, especialmente no que se refere à individualização do educando, pela atividade livre e espontânea e pelo estímulo à sua atividade criadora. Afastou-se, também, da proposta educacional dos intelectuais do ISEB, no que se refere ao seu papel de abrir a percepção do educando para compreender e fazer frente às condições políticas e ideológicas com que se defronta como estudante e como futuro trabalhador.

Conforme uma das orientações da APO, o sucesso de um empreendimento resultaria da execução de projetos autônomos e descentralizados, para os quais se exigia a preparação de gerentes eficientes e eficazes. O I Plano Setorial de Educação (Brasil/MEC, 1971) foi elaborado em conformidade com essa orientação. Compunha-se de um conjunto de 33 projetos, entre eles, a Carta Escolar, o Movimento Brasileiro de Alfabetização (MOBRAL), o Centro de Integração Empresa-Escola (CIEE) e o Programa Intensivo de Mão-de-obra. Para facilitar a gestão descentralizada, como previa a APO, foram criados distritos geoeducacionais e orgãos especiais de gerência - a exemplo do Programa de Desenvolvimento do Ensino Médio (Prodem) e do Programa de Desenvolvimento do Ensino (PREMEN), cujas sedes se situavam fora do Distrito Federal. 
Para assegurar a coesão entre as ações e o controle do Estado, os órgãos especiais contavam com gerentes indicados e preparados por instâncias específicas do poder federal.

A qualidade educacional definia-se pelo objetivo de "formar um cidadão capaz de participar eficazmente das atividades produtivas da nação". Para tanto, "o saber que a escola democrática transmitirá terá de ser um saber das coisas e não um saber sobre as coisas, com que se contenta a escola tradicional" (Brasil/MEC, 1971, p. 15-16). Com essa proposta, o I Plano Setorial consolidou as teorizações do capital humano e do enfoque de mão-de-obra como bases doutrinárias para a educação brasileira.

Pelo controle do governo, logrou-se anular a manifestação de conflitos ideológicos, como previa a lógica de segurança nacional. Não se logrou, como previa a APO, assegurar a necessária coesão entre as ações descentralizadas. Os projetos autônomos reduziram-se a um conjunto de ações fragmentadas e sem impacto educacional, sendo paulatinamente descartados pelos sucessivos governos militares.

Nos dez anos seguintes, o sistema educacional foi objeto de reformas para atender ao crescente apelo social por expansão de vagas e, também, às exigências impostas pelo próprio desenvolvimento do país. Como consequência, ocorreu a ampliação significativa da oferta de educação pública em todos os níveis e o ensino fundamental foi ampliado para oito anos. Sob influência do capital humano e do enfoque de mãode-obra, as mudanças mais qualitativas deram-se no ensino secundário, com a substituição das disciplinas de cunho erudito e humanístico por outras de conteúdo técnico-profissional. Em resposta às demandas das classes sociais, média e alta, garantiu-se o princípio da continuidade para todo o ensino secundário (segundo grau), permitindo o acesso à universidade pelo exame vestibular. Esta exigência foi a que mais se destacou com respeito à qualidade do ensino médio.

Paralelamente aos movimentos nacionais, os organismos internacionais de crédito e cooperação técnica passaram a interferir gradativamente na definição da agenda educacional. O Banco Mundial, por exemplo, impôs-se como um dos parceiros mais atuantes, no período 1970-1990, intensificando o seu financiamento à educação básica. Os planos educacionais evidenciavam essa influência, referindo-se explicitamente ao banco como parceiro técnico e político. Recomendava-se, 
Políticas públicas para a qualidade da educação brasileira...

inclusive, que as experiências vivenciadas nos projetos fossem repassadas à totalidade do sistema educacional.

O II Plano Setorial (1975-79) manteve o veio doutrinário de formação do homem útil ao país (o termo mão-de-obra foi substituído por recursos humanos para o desenvolvimento). Explicitou-se a intenção de adequar o ensino básico ao novo setor produtivo, que se consolidava com base em tecnologias avançadas nos planos técnico, administrativo e organizacional. Foram mantidos os objetivos do I Plano: adequação dos conteúdos, métodos e técnicas de ensino às necessidades - regionais e locais - da clientela; adequação dos resultados do sistema educacional aos requerimentos da estrutura ocupacional; incremento da oferta de ensino, na modalidade escolar ou não-escolar; treinamento de docentes in loco; elaboração de modelos de objetivos de ensino; treinamento de pessoal, visando à modificação da conduta funcional dos trabalhadores (Brasil/MEC, 1975a, p. 53-55).

O plano de 1975 foi complementado por uma proposta intitulada Politica Nacional de Educação Integrada, inspirada em programas financiados pelo Banco Mundial para a região Nordeste, conhecidos como Projetos de Desenvolvimento Rural Integrados (PDRI). A intenção era articular o ensino de primeiro grau de áreas rurais ao mercado de trabalho, para garantir a meta de qualificação antecipada de mão-de-obra. ${ }^{4}$ Mobilizou-se, para isso, toda a estrutura do ensino de primeiro grau e do programa de alfabetização. O enunciado deixava clara a adesão ao pragmatismo econômico: "No caso particular do analfabetismo, a meta deve ser a ação do MOBRAL, de esgotar em pouco tempo o estoque de analfabetos adultos e, do sistema regular, de eliminar o reabastecimento desse estoque" (Brasil/MEC, 1975b, p. 49).

$\mathrm{Na}$ transição do governo militar ao civil, a educação foi alvo de outras demandas, especialmente por parte das classes médias. Argumentava-se que o ensino profissionalizante, notadamente no segundo grau, não tinha qualidade suficiente para permitir o acesso aos níveis superiores. Segundo esse entendimento, o ensino de qualidade restringia-se aos cursos propedêuticos oferecidos pelo setor privado, sob a denominação de cursinhos pré-vestibular e cujo acesso era restrito às classes sociais mais altas. De fato, durante o período de vigência da educação profissionalizante, a escola particular fora mais eficaz 
para prover o acesso aos cursos superiores. Era considerada, portanto, como a "escola de melhor qualidade".

As demandas sociais foram fortalecidas pela criação de fóruns científicos e acadêmicos, como a Associação Nacional de Pesquisa em Educação (ANPEd) e a Sociedade Brasileira para o Progresso da Ciência (SBPC). O III Plano Setorial para o período 1980-1985 buscou espelhar a ambiência democrática que marcou o final do governo militar. Sua elaboração deu-se por um processo de planejamento participativo, congregando entidades acadêmicas e representativas do setor educacional, além de pessoal técnico das administrações estaduais e municipais. Em atendimento aos reclamos das classes médias e altas, substitui-se a profissionalização obrigatória por uma alternativa menos rígida, conhecida como preparação para o trabalho.

No tocante à diversificação do ensino, o terceiro plano deu continuidade ao segundo, adequando os conteúdos, métodos e a organização da escola às especificidades de cada grupo social. Assim, as escolas de áreas mais pobres deveriam garantir a formação antecipada para o trabalho. Esta proposta foi executada no âmbito de dois programas nacionais (PRONASEC e PRODASEC). Ambos davam continuidade à política de educação integrada em periferias urbanas e zonas rurais, incluindo conteúdos de formação para o trabalho nas quatro primeiras séries do ensino fundamental (Brasil/MEC, 1980).

Este breve apanhado histórico mostrou que os planos educacionais adotaram majoritariamente a ideologia dos governos estabelecidos. A rigor, um plano governamental deveria ser um instrumento para catalisar as demandas emanadas dos campos científico e econômico e dos movimentos organizados da sociedade e, ainda, para equilibrar as tensões que se produzem no embate entre elas. No entanto, o que se verificou foi que os setores organizados da sociedade perderam ou ganharam espaço de participação, em função da estrutura - mais ou menos democrática - dos governos vigentes. O período militar, pela sua característica autoritária, marcou-se pelo arrefecimento da mobilização social e pela intensificação dos acordos de cooperação com agências de fomento econômico e bancos internacionais. A organização do ensino por níveis e modalidades, discriminados segundo as características de cada clientela, produziu um significado peculiar para a qualidade educacional. Grosso modo, reeditou-se a política discriminatória do Estado 
Políticas públicas para a qualidade da educação brasileira...

novo, ao se adaptar a estrutura e os conteúdos do ensino à divisão econômica do trabalho e das classes sociais.

Os planos da Nova República: tensão entre os movimentos sociais e a parceria internacional

O período que se seguiu ao regime militar (Nova República) foi profícuo para a mobilização de setores organizados da sociedade em prol de políticas sociais mais democráticas. As Conferências Brasileiras de Educação e o Fórum Brasileiro em Defesa da Escola Pública congregaram partidos políticos, educadores, estudantes, sindicatos, moradores de bairro e associações de pais, tendo como norte a elaboração de propostas para a futura Assembléia Nacional Constituinte de 1988. $\mathrm{O}$ ensino médio teve centralidade nos debates, dando origem ao documento: Subsídios para a elaboração de políticas para o ensino médio. Foi considerado o nível apropriado para o aprofundamento de uma educação de qualidade: aquela que trabalha conteúdos significativos (científicos, tecnológicos, filosóficos e artísticos), que "permitem o desvelamento dos fundamentos das relaçôes sociais e, sobretudo, das relações de produção". Essas proposiçôes revelavam um novo conceito de qualidade, que não se limitava aos aspectos técnicos e quantitativos do sistema, mas que deveriam contribuir para a construção de novo projeto hegemônico de sociedade (Brasil/MEC/INEP, 1989, p. 15).

No âmbito da política oficial, o Plano Setorial de Educação e Cultura para o período 1986-1989 integrou-se ao I Plano de Desenvolvimento da Nova República. Resumia-se a um elenco de metas educacionais, com o objetivo de superar o déficit educacional da população alijada da escola. Ao mesmo tempo em que os educadores discutiam suas propostas nas Conferências Nacionais de Educação, o MEC executava três programas financiados pelo Banco Mundial: um para as escolas técnicas industriais e agrícolas (EDUTEC) e dois para o ensino fundamental (EDURURAL e Monhangara), executados nas regiōes Norte, Nordeste e Centro-Oeste. As propostas oficiais para a qualidade da educação fundamental eram estreitamente vinculadas aos objetivos dos projetos internacionais, entre eles, a criação de uma sistemática de avaliação para medir o impacto desses programas no desempenho escolar dos municípios atingidos. Para tanto, o Plano de 1986 recomendava a 
preparação de planejadores e gestores nos âmbitos federal, estadual e municipal para o desenvolvimento de "processos gerenciais e organizacionais, com vistas a facilitar e agilizar a utilização dos insumos e produtos do setor e a avaliação dos seus resultados" (Brasil/MEC, 1986, p. 14-21). Pode-se considerar que essas experiências constituíram a base para a implantação do sistema de avaliação do ensino fundamental, que se consolidaria na década seguinte.

A década de 1980, especialmente no período pós-militar, foi profícua para a mobilização da sociedade. As Conferências Brasileiras de Educação e o Fórum Brasileiro em Defesa da Escola Pública reuniam os educadores em torno de outras propostas autonômicas para a educação pública. Segundo Saviani (2007b), este foi um momento de maturidade para a reflexão acadêmica, e, certamente, determinante para a qualidade da educação brasileira. Como exemplos, o autor cita a significativa ampliação da produção científica nesse campo e a influência dos educadores na proposta da Constituinte de 1988 e na LDB de 1996.

No final daquela década, o MEC negociava com o Banco Mundial outro acordo para o desenvolvimento da educação fundamental nos estados do Nordeste (Projeto Nordeste), cuja execução dar-se-ia na década de 1990. No plano das açóes, este acordo dava continuidade ao Projeto EDURURAL, encerrado em 1987. Uma das propostas do Banco era dar seguimento ao processo de avaliação externa desenvolvido nos projetos anteriores, desta feita, alcançando o desempenho do aluno, dos professores e da rede escolar. ${ }^{5}$ A proposta acordada entre o MEC e o Banco era estender a avaliação à totalidade do sistema educacional. De fato, as experiências avaliativas efetuadas nos âmbito dos acordos internacionais deram suporte aos projetos nacionais de avaliação que se consolidariam na década de 1990 e que se constituiriam a principal referência para a qualidade educacional.

Com a instalação do governo Collor de Melo, em 1990, implantou-se um ciclo nacional de estudos visando subsidiar o Plano de Ação do governo para o período 1990-1995. No que se refere ao setor educacional, foi produzida uma série de documentos contemplando os princípios, as diretrizes e metas para o setor. Em seus princípios, o plano afirmava o compromisso do Estado com a qualidade social da educação, mencionada como elemento central para a cidadania e para fazer frente às demandas da modernidade. 
Políticas públicas para a qualidade da educação brasileira...

Em termos concretos, as políticas traduziam-se pelo provimento de insumos educacionais, tais como: recursos humanos e materiais; manutenção da rede física; adoção de medidas para neutralizar a repetência e para garantir a permanência do aluno na escola; estabelecimento de conteúdos nacionais mínimos, enriquecidos por contribuições regionais e locais; implantação de um processo de avaliação permanente dos currículos e do desempenho da escola e dos alunos. Estas medidas, segundo o plano, constituiriam um investimento na qualidade do produto da ação educativa (Brasil/MEC, 1990b).

A qualidade da educação foi amplamente debatida em ciclos de estudos, congregando renomados educadores brasileiros, administradores dos diversos sistemas de ensino e estudiosos em geral, inclusive representantes do empresariado $^{6}$ (Brasil/MEC, 1990a). Este ciclo teve seu apogeu em amplo simpósio nacional organizado pelo Instituto de Pesquisa Econômica Aplicada (IPEA), em 1991, no qual foi debatido o tema "Qualidade, eficiência e equidade na educação básica", e, posteriormente, o Seminário Nacional sobre Medidas Educacionais, organizado pelo Instituto Nacional de Estudos Pesquisas Educacionais (INEP). As conclusões do simpósio foram encaminhadas ao Ministério da Educação como subsídio para a reformulação do projeto de lei das Diretrizes e Bases da Educação Nacional, já em tramitação no Congresso (ver Xavier, Plank \& Amaral Sobrinho, 1992). O conceito de qualidade educacional foi assim expresso no documento síntese:

Na definição da pauta mínima, deve o Ministério atuar com base em definições consensuais de satisfação de necessidades básicas de aprendizagem. Essas não podem mais ser referenciadas com categorias difíceis de serem identificadas e aferidas - como, por exemplo, a formação do espírito crítico -, mas por aspectos concretos que permitam o salto para a racionalidade tecnológica, que determinou mudanças produtivas nas ilhas da modernidade. (p. 9)

O trecho citado reitera o sentido da política avaliativa incluída no plano educacional do governo vigente (Brasil/MEC, 1990b), ao admitir que a qualidade educacional se produziria pela definição de objetivos educacionais que pudessem ser quantitativamente aferidos. A alusão à modernidade dizia respeito à intenção de modelar a educação segundo a nova estrutura de Estado que se instalava no Brasil e que afirmava a hegemonia política do neoliberalismo, com suas estratégias 
de Estado mínimo, controlado por sistemas nacionais de avaliação e de fiscalização, além da desideologização do debate educacional (Brasil/ MEC, 1990a).

No que se refere ao marco doutrinário, o texto reeditou a visão utilitária dos anos de 1970, segundo a qual o conhecimento escolar só é válido quando descreve dados objetivos, livres de valoração e de criticidade, porquanto seu objetivo é a formação profissional adaptada ao mercado de trabalho vigente. Nesse sentido, constitui uma contraposição ao enfoque social do conhecimento, cujo objetivo é desvelar ao indivíduo as contradições no campo das relações sociais e de produção, onde transitará não somente como trabalhador, mas também como cidadão. $\mathrm{Na}$ ótica social, a educação de qualidade não poderia prescindir do desenvolvimento do espírito crítico, inclusive para estimular a capacidade transformadora do indivíduo.

Apesar da intensa mobilização governamental em torno do setor educativo, os planos elaborados durante o período da Nova República e do governo Collor tiveram pouco impacto no cenário nacional. O primeiro caso pode ser explicado pela complexidade política que marcou a transição do regime militar ao governo democrático; o segundo, pela conturbada e descontínua administração Collor de Melo.

$\mathrm{Na}$ qualidade de ministro da Educação do governo Itamar Franco, que substituiu Collor de Melo, Murílio Hingel buscou imprimir um tom diferenciado à política educacional. De acordo com o ministro, o estabelecimento do Acordo Nacional de Educação configurava-se como um pacto de qualidade. No final de seu mandato ministerial, a Organização das Nações Unidas para a Educação e a Cultura (UNESCO) exigiu dos países membros a elaboração dos planos educacionais para a década, segundo a Declaração Mundial de Educação para Todos, resultante da Conferência Internacional de Jontien, em 1990. Com base nas recomendações da conferência, o Ministério da Educação elaborou o Plano Decenal de Educação Para Todos. Apesar do tom democrático e autonômico do ministro Hingel, o plano assumiu as orientações doutrinárias e as metas quantitativas do fórum internacional, entre elas, a prioridade conferida à ampliação do ensino fundamental, em detrimento do ensino médio; a previsão de uma série de ações para a qualidade do ensino, entre elas, a necessidade da implantação de um amplo sistema de avaliação da educação básica, com a finalidade de aferir a 
Políticas públicas para a qualidade da educação brasileira...

aprendizagem dos alunos do ensino fundamental e de prover informações para a avaliação e revisão de planos e programas de qualificação educacional (Brasil/MEC, 1993). No decorrer da década, estas políticas foram sendo confirmadas pela institucionalização do Sistema de Avaliação da Educação Básica (SAEB) e pela prioridade conferida à avaliação nos textos da Lei de Diretrizes e Bases da Educação (Brasil, 1996) e do Plano Nacional de Educação (Brasil, 2001). ${ }^{7}$

Desde então, os resultados da avaliação externa foram tomados como a principal referência para a qualidade da educação. Isto, certamente, não correspondia à proposta que os educadores lograram inserir na LDB/96 e que confirmaram no Plano Nacional de Educação de 2001, segundo a qual a qualidade educacional resultaria de um esforço para a construção coletiva de um projeto político-pedagógico que respeita a autonomia, a participação, a cultura e a identidade escolar. Conforme mostrou a prática dos anos seguintes, a avaliação externa foi utilizada como meio de adequar a qualidade do ensino escolar aos padrôes estabelecidos por agentes externos.

Planejamento escolar na perspectiva da produtividade: visão estratégica para a eficiência e avaliação externa como referência para a qualidade

A década de 1990 caracterizou-se pela reestruturação do sistema econômico mundial e pelas demandas da chamada revolução tecnológica ou revolução informacional. Os países realizaram reformas educacionais para ampliar o grau de articulação do processo de formação escolar a essas demandas. O governo de Fernando Henrique Cardoso, eleito para dois mandatos seguidos (1995-2002), implementou uma série de mudanças no âmbito da chamada Reforma do Estado (Brasil/MARE, 1995). A primeira delas foi a substituição da administração pública burocrática pela administração gerencial. Foi elaborado o plano plurianual de governo (principal instrumento de planejamento instituído pela Constituição Federal de 1988). As ações foram organizadas na forma de projetos, interligados em rede nacional, cada um sob a responsabilidade de um gerente. ${ }^{8}$ Vale lembrar que, embora fosse apresentada com inovação, a modalidade de administração por projetos já havia sido adotada na reforma administrativa do setor público, deflagrada pelo Decreto-Lei n. 200, de 1967. 
As mudanças educacionais implementadas no país seguiram as orientações da Reforma do Estado e foram incluídas no plano plurianual do MEC. A qualidade da educação escolar resultaria de uma adequada revisão curricular, da eficiência da gestão institucional e da competitividade deflagrada por um processo de avaliação externa. No primeiro mandato, a meta prioritária centrou-se na ampliação da oferta do ensino fundamental. No segundo, sob a justificativa da crescente exigência de qualificação do trabalhador para a nova estrutura do mercado, o ensino médio sofreu uma reforma, sendo desmembrado em duas modalidades distintas e independentes: o ensino médio, de conteúdos gerais, e o ensino técnico-profissionalizante. As mudanças qualitativas alcançariam os currículos, além da oferta de cursos de reciclagem, no caso do ensino profissional. Consoante o veio controlador que caracterizou a reforma do Estado, a escola básica passou a ser amplamente avaliada, mediante a implantação do Sistema de Avaliação da Educação Básica (SAEB). Os resultados foram utilizados como medida do desempenho da escola e do aluno e, portanto, constituíram a principal referência para a qualidade educacional.

Ao mesmo tempo, ocorria uma mobilização ampla em torno da elaboração do Plano Nacional de Educação (aprovado pelo Congresso em 2001). Segundo Sena (2000), a construção desse plano deu-se em meio a processos paralelos, oriundos do executivo, do legislativo e dos setores reivindicativos. Um deles resultou de um processo de consulta do MEC, dirigida a diferentes entidades representativas, tais que a União Nacional de Dirigentes Municipais de Ensino (Undime) e o Conselho de Secretários de Estado de Educação (CONSED). Paralelamente, os educadores construíam suas propostas em fóruns nacionais. Em meio ao debate, um terceiro processo foi deflagrado pela Comissão de Educação, Cultura e Desporto da Câmara Legislativa, com a intenção de conciliar os dois anteriores. Para o autor, a despeito dessa polarização, o Plano abriu oportunidade para a construção de planos estaduais e municipais, além de constituir um instrumento de longo prazo, de forma que as metas educacionais não ficassem a reboque das diretrizes orçamentárias e políticas dos Planos Plurianuais de Governo (PPA).

De modo geral, as metas do plano centravam-se na equalização de oportunidades. Destacou-se a universalização da educação fundamental e a expansão da educação infantil, do ensino médio e superior, além da reorganização e ampliação do financiamento, pela constituição 
Políticas públicas para a qualidade da educação brasileira...

de fundos contábeis, tal como o Fundo de Manutenção e Desenvolvimento do Ensino Fundamental e de Valorização do Magistério (FUNDEF). Nos itens específicos para a qualidade, não se logrou alcançar a amplitude que o tema merecia. As metas referiam-se à implantação de planos de carreira para os profissionais do magistério e à criação de um Sistema Nacional de Avaliação. Os padrōes mínimos de qualidade da aprendizagem, embora constituíssem uma das metas, não foram especificados no plano. Sugeriu-se a realização de uma futura Conferência Nacional de Educação para a sua especificação.

Como uma das metas fixadas pelo PNE, o FUNDEF também ocupou o centro dos debates como uma das principais políticas para o fortalecimento da educação nacional. Implementado em 1998, o FUNDEF buscou adequar o aprendizado ao conceito operacional de custo-alunoqualidade, traduzido pela quantidade e variedade dos insumos necessários ao processo de ensino-aprendizagem, com um nível mínimo de despesas. Desse modo, as propostas apenas tangenciavam a qualidade educacional ao dar centralidade aos meios - ou insumos - para lograr a equidade na oferta de ensino e o controle social sobre os recursos.

Uma das metas mais relevantes do Plano referia-se à gestão escolar. Reiterou-se o dispositivo contido no inciso I do artigo 13 da LDB/ 96, que atribuía ao estabelecimento escolar a elaboração e execução do seu Projeto Político Pedagógico (PPP). Tal projeto traduzia a aspiração dos educadores comprometidos com uma educação de qualidade, como ação mediadora do diálogo entre a escola, o campo científico e as instâncias de decisão política.

Em 1998, o movimento dos educadores sofreu uma concorrência de porte internacional. Embora o ppp fosse considerado - nos textos legais e no plano plurianual do governo vigente - como um dos pilares para a qualidade da educação, o MEC assinou um novo acordo de financiamento com o Banco Mundial, para a melhoria da qualidade das escolas fundamentais das regiões Norte, Nordeste e Centro-Oeste: o Fundo de Desenvolvimento da Escola Básica (fundescola). O acordo estabelecia a adoção de uma modalidade de planejamento escolar conhecida como Plano de Desenvolvimento da Escola (PDE). A qualidade educacional seria alcançada pela adequada combinação de insumos escolares (pacotes didáticos, equipamentos, reformas), pelo repasse de dinheiro direto à escola e por um modelo de gestão capaz de utilizar 
esses insumos eficientemente. O PDE-escola, portanto, afirmava a pura racionalidade técnica, contradizendo o sentido político que os educadores requeriam para um projeto escolar de qualidade. No entanto, recebeu amplo apoio técnico e financeiro do MEC e das administrações estaduais, o que possibilitou a sua instalação definitiva nas escolas. Sendo negociado como um projeto de longo prazo, a influência do FUNDESCOLA ultrapassou as fronteiras do governo de Fernando Henrique Cardoso, pelo fato de que, por força do acordo, seu término fora previsto para o ano de 2010 (Fonseca, Oliveira \& Toschi, 2004).

A política do novo governo eleito para o período 2003-2007 adotou a justiça social como marco doutrinário. Buscou imprimir um círculo virtuoso entre investimento e consumo, por meio de políticas sociais que compensassem a sua fragilidade no campo econômico-social. No que se refere ao projeto educacional, reiterou o objetivo da gestão anterior, de universalizar a educação básica e de ampliar a oferta do nível médio. Os recursos para a educação básica, centrados no Fundo de Manutenção e Desenvolvimento do Ensino Fundamental e de Valorização do Magistério (FUNDEF), foram estendidos ao ensino médio com a aprovação do Fundo de Manutenção e Desenvolvimento da Educação Básica (FUNDEB). Comparativamente ao viés economicista do governo anterior, o Plano Plurianual 2003-2007 expressava uma tendência social mais acentuada, com o intuito de corrigir a histórica desigualdade entre regiões, pessoas, gêneros e raças.

Em 2007, o governo lançou o Plano de Desenvolvimento da Educação ( $\mathrm{PDE}$ ), propondo trinta metas para enfrentar os desafios da qualidade, das quais dezessete se referem ao ensino básico. Desde então, o Plano vem sendo submetido a debates em que se confrontam seus pontos frágeis e suas potencialidades com respeito à qualidade educacional. Saviani (2007) aponta, como uma das fragilidades do PDE, o fato de que suas metas se limitem a um conjunto de ações sem a organicidade necessária para se constituir em um plano político de governo. Muitas destas açôes não interagem entre si e, tampouco, com as propostas do Plano Nacional de Educação de 2001. O autor considera que, pelo fato de ter sido debatido em muitos fóruns nacionais, o Plano de 2001 constitui uma referência para os educadores e, portanto, não poderia ser ignorado no atual PDE. 
Políticas públicas para a qualidade da educação brasileira...

De outro lado, são ressaltadas algumas medidas positivas, como a nova modalidade de avaliação do desempenho escolar, com o objetivo de levar assistência técnica aos municípios com os mais baixos índices de qualidade educacional; as propostas para a melhoria da profissionalização docente, pelo estabelecimento de jornada integral de trabalho em uma única escola e a destinação de tempo para atividades fora da sala de aula; a formação de nível superior para os professores não-graduados, além de outras formas de educação continuada: presencial e a distância. Um dos pontos de destaque é que a formação para o ensino básico passa a ser atribuição da CAPES, antes responsável apenas pela formação de professores de nível superior. Argumenta-se que a ação reguladora da CAPES possa imprimir qualidade à educação continuada, na medida em que o processo seja mais duradouro, evitando-se a sua fragmentação em miríades de cursos curtos e desarticulados - tal como ocorrera em experiências anteriores -, subtraindo momentos de folga dos professores.

Pelo fato de ser um projeto em fase de implantação, o PDE deverá ser objeto de estudos e debates em todas as fases de sua execução. Alguns questionamentos já são recorrentes nos debates entre os educadores: em que medida o PDE ensejará uma gestão escolar mais autônoma e participativa, contrapondo-se à visão gerencial disseminada nos anos de 1990? A adoção da Prova Brasil e da Provinha Brasil poderá constituir uma alternativa para o modelo vigente de avaliação externa, superando o mero objetivo de controle de produtos? A formação de professores contará com recursos suficientes para que se constitua em ação contínua e duradoura? Atingirá a educação média, na medida de suas necessidades? A distribuição dos recursos garantirá o equilíbrio necessário entre formação presencial e a distancia? Em que medida contará com a participação dos setores públicos e privados?

\section{Considerações finais}

É possível concluir que, durante as últimas décadas, a qualidade educacional oscilou em meio a múltiplas influências. Os planos incorporaram, com mais ou menos intensidade, o substrato econômico que sustentou os diferentes projetos nacionais de desenvolvimento. A mobilização dos educadores representou um espaço para a construção 
de propostas mais autônomas e socialmente mais relevantes para a educação brasileira. Essa ambivalência expressou-se nos enunciados humanistas dos planos e do corpus legislativo, ressaltando a igualdade de oportunidades para todos, a gestão democrática do sistema e o compromisso ético com a qualidade educacional, conforme requeriam os educadores. Na prática, a ação educativa deu ênfase a programas e projetos orientados pela lógica do campo econômico, dirigindo a ação escolar para as atividades instrumentais do fazer pedagógico e para a administração de meios ou insumos. A qualidade, por sua vez, foi sendo legitimada pelo horizonte restrito da competitividade, cuja medida é a boa colocação no ranking das avaliações externas.

Se esse enfoque utilitarista serve à excelência empresarial, não é suficiente para orientar a qualidade da ação educativa. Nesse campo, a qualidade tem como horizonte as diferentes dimensóes da vida social. Exige, portanto, uma interação constante entre a política educacional e os campos da ciência, da cultura, da cidadania e da ética. Este é um horizonte de longo alcance que a escola não pode alcançar em seu isolamento. Portanto, a sociedade espera que o Estado faça a sua parte. Primeiro, atuando como poder mediador, capaz de catalisar as demandas emanadas do campo científico e econômico, da comunidade educacional e das famílias e de conduzi-las ao encontro de um projeto educacional que contemple todas as dimensões do conhecimento humano. Segundo, exercendo sua capacidade equalizadora, no sentido de prover condiçóes para a superação das dificuldades que afligem os entes administrativos locais (orçamentárias, gestionárias, pedagógicas e culturais). Enfim, espera-se que o Estado cumpra sua função mais genuína, a de preparar os profissionais da escola para que possam agir como sujeitos centrais no processo de construção de um projeto educacional de qualidade.

Recebido em novembro de 2007 e aprovado em agosto de 2008.

\section{Notas}

1. Embora influenciado pelo pragmatismo de Dewey (à época, foco de acirrada polêmica entre os educadores brasileiros), Anísio Teixeira desenvolve uma visão peculiar, segundo a qual a educação escolar se limitaria à formação para o desenvolvimento econômico, mas como forma de suplantar o dualismo social, preparando o indivíduo para uma inserção social democrática, igualitária e participativa. 
Políticas públicas para a qualidade da educação brasileira...

2. A política educacional, no período que antecedeu ao golpe militar, foi expressa em três documentos elaborados com a assessoria do Conselho Federal de Educação: o Plano Nacional de Educação e o Programa de Emergência do Ministério da Educação e Cultura, para o ano de 1962. Em 1963, foi elaborado o plano definitivo (Plano Trienal de Educação), para o período 1963-1965. Com o governo militar, ele foi substituído pelo plano de 1965.

3. APO é uma variante da teoria neoclássica, que tem como foco a ação e os seus resultados. Portanto, é pragmática e prescritiva, como mostram as suas próprias diretrizes: a) pauta-se pelo racionalismo ou comportamento segundo as prescrições do sistema; b) enfatiza os objetivos e os resultados, isto é, a parte instrumental da administração; c) planeja para a eficiência (custo-benefício) e a eficácia (resultados de impacto ou produto); d) descentrali$z a$ a ação para aumentar a eficiência.

4. Os PDRI eram administrados pelo Ministério da Agricultura. Desenvolviam ações educativas voltadas para o ingresso imediato no mercado de trabalho, especialmente o mercado não-institucionalizado ou setor informal, que pode absorver até $60 \%$ da mão-deobra urbana, constituído de atividades manuais simples, como artesanato, pequeno comércio e serviços gerais. São serviços que exigem técnicas simples e conhecimentos pouco especializados, que poderiam ser obtidos fora do ensino formal.

5. A primeira iniciativa deu-se no ano de 1988, no marco de um convênio entre o MEC e o Instituto Interamericano de Cooperação para a Agricultura (IICA), com a participação técnica da Fundação Carlos Chagas. O convênio respondia a uma demanda do Banco Mundial para desenvolver uma sistemática de avaliação para o futuro Projeto Nordeste - um acordo que se encontrava em fase de negociação entre o MEC e o Banco para o financiamento da educação fundamental na região Nordeste (executado na década de 1990). A intenção era estender essa sistemática de avaliação para o sistema educacional em nível nacional (Brasil/ MEC/SENEB, s./d.). Em novembro de 1988, foi aplicado o teste piloto da avaliação nos estados do Paraná e do Rio Grande do Norte. No mesmo ano, o MEC estendeu o processo para todo o Brasil, ampliando-se a abrangência da avaliação proposta pelo Projeto Nordeste. Surgiu, assim, o Sistema de Avaliação do Ensino Público de $1^{\circ}$ Grau (SAEP). Devido a problemas orçamentários, os trabalhos só foram retomados em agosto de 1990, ano em que ocorreu a primeira avaliação em nível nacional. Em 27 de dezembro de 1994, o ministro da Educação Murílio Hingel institucionalizou o Sistema Nacional de Avaliação da Educação básica (SAEB) (Horta Neto, 2006).

6. O Instituto Herbert Levy ( $\mathrm{IHL}$ ) e a Confederação Nacional da Indústria (CNI) divulgaram um documento contendo um conjunto de requisitos básicos para a melhoria da educação brasileira. Recomendava-se o desenvolvimento de competências exigidas pela revolução tecnológica, de forma a preparar o indivíduo de acordo com os novos requisitos do mercado: um profissional mais flexível, polivalente ou multifuncional, capaz de adaptar-se aos requisitos da nova estrutura do trabalho. O documento recomendava, também, um controle de qualidade, mediante a instalação de um processo de avaliação externa do ensino básico.

7. A LDB n. 9.394/96, em seu artigo 9º inciso v, dispõe que "cabe à União a coleta, a análise e a disseminação de informações sobre educação". O inciso VI, desse mesmo artigo, estabelece também que a União, em colaboração com os sistemas estaduais e municipais de ensino, deve assegurar um processo nacional de avaliação do rendimento escolar nos dois níveis de ensino, com o objetivo de definir prioridades para melhorar a qualidade do ensino. O Plano Nacional de Educação de 2001 também estabelece que sejam implementados, em todos os Estados da Federação, programas de formação do pessoal 
técnico das secretarias para suprir as necessidades dos setores de informação e estatísticas educacionais, planejamento e avaliação.

8. Os gerentes eram designados pelos ministros e deveriam ser pessoas qualificadas, com sólida experiência profissional, grande conhecimento técnico e gerencial, capacidade de negociação e de motivação, além de espírito de liderança. A formação dos gerentes concentrava-se nas áreas de engenharia e economia (Brasil/Ministério do Planejamento, Orçamento e Gestão, 2002).

\section{Referências}

BAIA HORTA, J.S. Liberalismo, tecnocracia e planejamento educacional no Brasil. São Paulo: Cortez, 1982.

BRASIL. Câmara Legislativa. Plano Nacional de Educação; projeto de lei. Brasília, DF: CL, 1937.

BRASIL. Lei n. 9.394, de 20 de dezembro de 1996. Dispõe sobre as Diretrizes e Bases da Educação Nacional. Diário Oficial da União, Brasília, DF, 23 dez. 1996.

BRASIL. Lei n. 10.172, de 9 de janeiro de 2001. Aprova o Plano Nacional de Educação e dá outras providências. Diário Oficial da União, Brasília, DF, 10 jan. 2001.

BRASIL. Ministério da Administração e Reforma do Estado. Plano Diretor da Reforma do Estado. Brasília, DF: MARE, 1995.

BRASIL. Ministério da Educação. Plano Nacional de Educação. Brasília, DF: MEC, 1962.

BRASIL. Ministério da Educação. Programa de Emergência do Ministério da Educação. Brasília, DF: MEC, 1962.

BRASIL. Ministério da Educação. Plano Trienal de Educação. Brasília, DF: MEC, 1963.

BRASIL. Ministério da Educação. Plano Nacional de Educação; revisão de 1965. Brasília, DF: MEC, 1965.

BRASIL. Ministério da Educação. I Plano Setorial de Educação e Cultura 1972-74. Brasília, DF: MEC, 1971.

BRASIL. Ministério da Educação. II Plano Setorial de Educação e Cultura. Brasília, DF: MEC, 1975a. 
Políticas públicas para a qualidade da educação brasileira...

BRASIL. Ministério da Educação. Política Nacional Integrada da Educação. Brasília, DF: MEC, 1975b.

BRASIL. Ministério da Educação. III Plano Setorial de Educação e Cultura: 1980-1985. Brasília, DF: MEC, 1980.

BRASIL. Ministério da Educação. Plano Setorial de Educação e Cultura: 1986-1989. Brasília, DF: MEC, 1986.

BRASIL. Ministério da Educação. Ciclo de estudos: modernidade e educação básica. Brasília, DF: MEC, 1990a

BRASIL. Ministério da Educação. Programa setorial de ação do Governo Collor na área de Educação. Brasília, DF: MEC, 1990b.

BRASIL. Ministério da Educação. Plano Decenal de Educação para Todos. Brasília, DF: MEC, 1993.

BRASIL. Ministério da Educação. Secretaria de Ensino Básico (sEneb) Sistema nacional de avaliação da educação básica (estudo preliminar). Brasília, DF: MEC, [s.d.].

BRASIL. Ministério da Educação. Instituto Nacional de Estudos e Pesquisas Educacionais (INEP). Subsidios à elaboração de políticas para o ensino médio. Brasília, DF: MEC; INEP, 1989.

BRASIL. Ministério do Planejamento, Orçamento e Gestão. O desafio do planejamento governamental. Brasília, DF: MP, 2002.

BRASIL. Ministério do Planejamento, Orçamento e Gestão. Plano Plurianual 2004-2007. Brasília, DF: MEC, 2004.

CUNHA, L.A. O desenvolvimento meandroso da educação brasileira entre o Estado e o mercado. Educação \& Sociedade, Campinas, v. 28, n. 100, p. 809-829, out. 2007.

FONSECA, M.; OLIVEIRA, J.F.; TOSCHI, M.S. Escolas gerenciadas: planos de desenvolvimento e projetos político pedagógicos em debate. Goiânia: UCG, 2004.

HORTA NETO, J.L. Avaliação externa: utilização dos resultados do SAEB na gestão do sistema público de ensino fundamental no Distrito Federal. 2006. Dissertação (Mestrado) - Programa de Pós-Graduação em Educação, Universidade de Brasília, Brasília, DF. 
OLIVEIRA, R.P. Da universalização do ensino fundamental ao desafio da qualidade: uma análise histórica. Educação \& Sociedade, Campinas, v. 28, n. 100, p. 661-690, out. 2007.

SAVIANI, D. O Plano de Desenvolvimento da Educação: análise do projeto do MEC. Educação \& Sociedade, Campinas, v. 28, n. 100, p. 1231-1255, out. 2007a.

SAVIANI, D. História das ideias pedagógicas no Brasil. Campinas: Autores Associados, 2007b.

SCHWARTZMAN, S.; BOMENI, M.B.; COSTA, V.M.R. Tempos de Capanema. São Paulo: Paz \& Terra, 1984.

SENA, P. O plano nacional de educação na Câmara dos Deputados: por um PNE já. Cadernos Legis, Brasília, DF, v. 4, n. 10, p. 64-72, jan./ abr. 2000 .

VIEIRA, S.L. Politica educacional no Brasil: introdução histórica. Brasília, DF: Líber livro, 2007.

XAVIER, A.C.R.; PLANK, D.N.; AMARAL SOBRINHO, J. (Org.). Padrões mínimos de qualidade dos serviços educacionais: uma estratégia de alocação de recursos para o ensino fundamental. In: GOMES, C.A.; Amaral Sobrinho, J. (Org.). Qualidade, eficiência e equidade na educação básica. Brasília, DF: IPEA, 1992. p. 71-97. 